\title{
Acidente vascular cerebral e outras complicações do Sistema Nervoso Central nas doenças falciformes
}

\author{
Stroke and other vascular complications of the Central Nervous System in sickle cell disease
}

Ivan L. Angulo

\section{Introdução}

A causa mais comum de acidente vascular cerebral (AVC) na infância é a anemia falciforme, o homozigoto da hemoglobina S ou Hb SS. A doença falciforme (Hb SS e interações com outras hemoglobinopatias e talassemias) é a principal enfermidade genética da população brasileira, com 13.500 pacientes catalogados em 2006, com prevalência populacional do gene S de 1/1.200 pessoas. ${ }^{1}$ Manifesta-se com lesões em vários órgãos, causando elevada morbidade e mortalidade.

Dentre essas lesões, a principal, na infância, é a das artérias cerebrais, mas após os 20 anos também pode se manifestar, como seqüela de lesões anteriores ou neoformadas. ${ }^{2}$ A vasculopatia tem a maior importância no desenvolvimento da criança e na qualidade de vida. ${ }^{3}$ Além do acidente vascular cerebral (AVC), completo ou incompleto ("silenci- oso"), existem outras complicações do sistema nervoso central, porém não exclusivas da doença falciforme, como convulsões, encefalopatia, hipertensão intracraniana, trauma, meningite, alterações mentais por distúrbios metabólicos e neuropatia periférica ou hipertensão intracraniana por oclusão venosa. ${ }^{3}$

Com exceção do AVC, o diagnóstico da vasculopatia cerebral falciforme não pode ser feito clinicamente, necessitando auxílio neurorradiológico ou por outros meios. O tratamento se faz basicamente com transfusões de eritrócitos contendo hemoglobina A.

O objetivo deste trabalho é rever a literatura médica, procurando selecionar a melhor conduta em diagnóstico e tratamento que seja possível empregar de imediato, para reduzir a morbidade e mortalidade da vasculopatia cerebral e elevar a qualidade de vida dos pacientes, principalmente na infância.

Assessor médico da Fundação Hemocentro. Médico do Centro Regional de Hemoterapia do Hospital das Clínicas da Faculdade de Medicina de Ribeirão Preto - USP.

Correspondência: Ivan de Lucena Angulo

Rua Tenente Catão Roxo, 2.501 - Campus da USP - Monte Alegre

14051-140 - Ribeirão Preto-SP - Brasil

Tel.: (16)2101-9300 - Fax.: (16)2101-9309

E-mail: angulo@pegasus.fmrp.usp.br 


\section{Material e Métodos}

Consulta à base de dados Embase (www.embase.com - acesso em 08/01/2007) a partir de 2003, ao Entrez PubMed www.ncbi.nlm.nih.gov/entrez - acesso em outubro 2006), e à Cochrane Library (http://cochrane.bireme.br/cochrane acesso em 14/12/2006). Fizemos também uma revisão de dados não publicados da casuística do ambulatório de anemias do Centro Regional de Hemoterapia do Hospital das Clínicas da Faculdade de Medicina de Ribeirão Preto da Universidade de São Paulo.

\section{Resultados}

Selecionamos alguns artigos considerados relevantes para revisão do conhecimento aplicado sobre a prevalência, etiologia e fisiopatologia, estimativa de risco, diagnóstico e tratamento da vasculopatia cerebral falciforme. As conclusões do SCD Global Experts and Regional Advisory Board Latin America ${ }^{1}$ serão apresentadas no final. Os artigos selecionados discorrem sobre o AVC agudo isquêmico (AVCi) ou hemorrágico (AVCh), portanto pacientes com sinais e sintomas neurológicos agudos, assim como sobre a isquemia cerebral "silenciosa" (ICS), isto é, evidências radiológicas ou funcionais na ausência de sinais e sintomas neurológicos, pacientes assintomáticos, portanto.

No Centro Regional de Hemoterapia realizamos, em novembro de 2000, estudo com imagens de ressonância magnética (IRM) e angiorressonância (ARM) em 47 pacientes acima de 14 anos de idade, sendo 18 normais, 29 anormais, porém nove destes com alteração bilateral de baixo fluxo no sifão carotídeo, considerado falso-positivo, encontrando, portanto, 42,5\% (vinte pacientes) com lesões cerebrais residuais de isquemia cerebral e/ou vasculopatia. Os resultados destes vinte pacientes, (dez masculinos) foram os seguintes: lesão vascular em 13; estenose/obstrução/estreitamento, 11; aneurisma, um; moyamoya, um; lesão na artéria cerebral média, cinco; na artéria cerebral anterior, cinco; na artéria cerebral posterior, um; na carótida interna, três; lesão em parênquima, 15, sendo gliose 11, encefalomalácea quatro, infartos três; locais mais acometidos: núcleos da base, dois; cerebelo, um; tálamo, um. Lesões mistas, vascular e parênquima, nove. Estudamos também, a partir de 2004, com Doppler Color Duplex (DTCi), e como parte da rotina, todas as crianças dos 2 aos 18 anos, complementando com IRM e angiorressonância (ARM) nos casos com valores alterados do fluxo cerebral no Doppler. De cem crianças estudadas, havia 28 com elevação do fluxo e duas com redução, os seja, 30\% com valores alterados. Destes últimos, 14 realizaram o estudo completo e 16 aguardavam vaga para as imagens de ressonância. Dos 14 analisados, quatro tiveram os resultados de ARM normais e dez apresentavam lesões, sendo sete com Hb SS (anemia falciforme, homozigoto), dois S-beta talassemia e um com interação SC (sete meninas e três meninos). A carótida interna foi a mais acometida (cinco casos), seguida pela artéria cerebral média (três casos, um concomitantemente com lesão na carótida), dois casos com estenoses ou oclusões não-especificadas e um com moyamoya.

\section{Conclusões}

A lesão isquêmica cerebral aguda sintomática ou AVCi ocorre em $10 \%$ a $18 \%$ dos pacientes brasileiros. ${ }^{2}$ Em outros países, oscila entre 1\% (Arábia Saudita) e 10\% (EUA). Na ausência de tratamento, recorrência do evento acontece em 2/3 dos casos. As lesões cerebrais são progressivas, agravando as deficiências neurológicas funcionais. Aos 20 anos de idade, 11\% e, aos 45 anos, 24\% dos pacientes já tiveram AVCi. A maior incidência ocorre nas crianças entre 2 a 9 anos, voltando a aumentar após os 20 anos, sendo a média das idades em 13,8 anos. O risco de isquemia cerebral (sintomática ou silenciosa) no decorrer da vida do paciente é de $30 \%$. O acidente vascular hemorrágico ou AVCh, mais comum após os 20 anos, apresenta média de idade de 31,7 anos. É conseqüência do rompimento dos pequenos vasos de circulação colateral após lesões isquêmicas, denominadas moyamoya. ${ }^{4}$ A mortalidade oscila entre 24\% a 50\%. Estudos em autópsias revelaram que o AVC é responsável por 9,8\% das mortes nos EUA em pacientes do CSSCD - estudo multicêntrico norteamericano $^{5}$ ou Cooperative Study Sickle Cell Disease . No Brasil, estudo realizado no Hemocentro do Rio Grande do Norte encontrou causas cerebrais em 9\% dos óbitos, semelhante às causas infecciosas, e inferior à síndrome torácica e seqüestro esplênico. ${ }^{6}$

A lesão isquêmica "silenciosa" ou ICS, isto é, aumento da intensidade do sinal em imagens anormais de ressonância magnética (IRM) do cérebro, sem manifestações clínicas de deficiência neurológica que durem mais que 24 horas, tem o dobro da prevalência do AVC (17\% a 22\% aos 20 anos). No entanto, utilizando técnicas neurorradiológicas avançadas, podemos encontrar lesões em $44 \%$ a $49 \%$ dos pacientes. ${ }^{4}$ É a lesão cerebral mais freqüente, acometendo $11 \%$ até os 4 anos e 22\% aos 14 anos das crianças com anemia falciforme, 6\% das crianças com interação SC e 15\% com S $\beta$ talassemia.

A lesão isquêmica "silenciosa" causa várias deficiências neurocognitivas, como problemas de aprendizado e redução do Quociente de Inteligência (QI). Afeta os lobos frontais causando deficiência da atenção, falta de habilidades executivas, da memória ativa e de longo prazo, envolvendo, dessa forma, médicos, familiares e os professores. As imagens anormais na IRM são em T2 por aumento da intensidade do sinal compatível com infarto e acima de $3 \mathrm{~mm}$. Há falsos-positivos, como lesões de encefalomielite, seqüelas de leucomalácia e mielinização alterada. Associados são atrofia cerebral e moyamoya, sem história, achados físicos, ou sinais focais de deficiência neurológica de mais de 24 horas de duração. As crianças estão sob risco de progressão de lesões neurológicas, como AVC (predispõe a AVCi, principal- 
mente se associada a velocidades de fluxo alteradas no Doppler), novas lesões na IRM, baixo desempenho escolar e baixo QI. Os fatores de risco associados são baixa freqüência de CVO, convulsões, leucocitose acima de 11.800, haplótipo SEN, porém sem valor preditivo. O risco de AVC é de $8 \%$, sendo de $0,5 \%$ nas crianças sem ICS. ${ }^{7} \mathrm{O}$ tratamento sugerido são transfusões crônicas, que parecem interromper o surgimento de novas lesões, mas estas lesões são de patologia microvascular, sendo incerto o seu benefício. Deve-se aguardar o resultado de um novo trial (SITT), que compare grupos com e sem transfusões. Uma opção sem provas de sucesso é o emprego de hidroxiuréia. Uns poucos casos se beneficiaram do TMO. Os programas de recuperação neurofuncional são aparentemente bem sucedidos. ${ }^{7} \mathrm{O}$ quadro 1 (Hoppe, 2004) ${ }^{8}$ compara as duas entidades.

O fenótipo S homozigoto (Hb SS - anemia falciforme) é considerado de maior risco ${ }^{9}$ do que as interações SC e STalassemia beta, assim como antecedentes de ataque isquêmico transitório (TIA), anemia, leucocitose, hipertensão arterial, síndrome torácica aguda prévia, hipoxemia, irmãos com AVC, antígenos HLA e polimorfismo da VCAM (molécula de adesão célula-endotélio). $\mathrm{O}$ infarto isquêmico pode se originar de lesões das grandes artérias do círculo de Willis, por hiperplasia da camada íntima e proliferação muscular e de fibroblastos, culminando na formação de trombos por outros fatores que seriam ativação da coagulação, presença de inflamação, ação de anticorpos antifosfolípides, ativação de células endoteliais, particularmente da VCAM, adesão de leucócitos e eritrócitos ao endotélio e desregulação da produção de óxido nítrico (NO). ${ }^{10}$ Há fatores de risco desfavoráveis (grau de anemia, leucocitose, hipertensão arterial, síndrome torácica aguda anterior, infecção por Clamidia, aterosclerose, hipoxemia aguda, TIA ou ataque isquêmico transitório ou evento neurológico anterior, presença de moyamoya, presença de inflamação e baixa ocorrência de crises vaso-oclusivas) e favoráveis (presença de alfa talassemia e interação SC). Outros genes modificadores podem estar implicados no risco ou na proteção de AVC. ${ }^{11}$

Outros estudos dirigidos aos fatores de risco ${ }^{4}$ identificaram os seguintes:

\section{Clínicos}

- idade 2 a 8 anos, devido ao fluxo cerebral elevado

- irmão Hb SS com AVC

- presença de isquemia cerebral silenciosa (ICS)

- ataque isquêmico transitório ou TIA (paralisia ou fraqueza de membros com 24 horas de duração) anterior

- infecção pelo parvovírus B19, crise aplástica

- meningite bacteriana

- síndrome torácica aguda recorrente com hipoxemia grave

- hipoxemia noturna, com ou sem apnéia no sono

- anemia aguda, com queda da $\mathrm{Hb}$ de mais de $2 \mathrm{~g} / \mathrm{dl}$ do valor basal

- convulsões repetidas

- dactilite antes de um ano de idade

- disfunção ou infarto esplênico com um ano de idade

- priapismo

- hipertensão sistólica

- sinais de disfunção neuropsicológica (baixo rendimento escolar, baixo desempenho em testes de atenção, incapacidade de realização de tarefas que exigem habilidade manual fina).

Quadro 1. Comparação entre as lesões vasculares cerebrais na doença falciforme. Hoppe, $2004^{8}$, modificada.

\begin{tabular}{|c|c|c|c|}
\hline & AVCi & AVCh & ICS \\
\hline $\begin{array}{l}\text { Idade da } \\
\text { maior incidência }\end{array}$ & $2-5$ anos & 20-29 anos & $\begin{array}{l}22 \% \text { aos } 6-12 \text { anos; } \\
\text { número de lesões } \\
\text { aumenta com a idade }\end{array}$ \\
\hline Apresentação & $\begin{array}{c}\text { Hemiparesia, afasia, } \\
\text { deficiência hemisensorial ou } \\
\text { defeitos visuais, } \\
\text { sinais focais (convulsões) }\end{array}$ & $\begin{array}{c}\text { Cefaléia grave, alteração da } \\
\text { consciência, convulsões, } \\
\text { síncope }\end{array}$ & $\begin{array}{c}\text { Ausência de sintomas } \\
\text { neurológicos; } \\
\text { disfunção neurocognitiva }\end{array}$ \\
\hline Neuroimagens & $\begin{array}{l}\text { IRM: infarto na região de } \\
\text { carótida ou ACM/ ARM: } \\
\text { estenose, oclusão, } \\
\text { moyamoya }\end{array}$ & $\begin{array}{c}\text { Hemorragia subaracnóidea } \\
\text { ou intracerebral por } \\
\text { rutura de aneurisma } \\
\text { ou moyamoya }\end{array}$ & $\begin{array}{l}\text { Infartos arteriais borderzone; } \\
\text { oclusão dos pequenos vasos }\end{array}$ \\
\hline Local das lesões & $\begin{array}{l}\text { Lobos frontal, parietal e } \\
\text { temporal, gânglios da base, } \\
\text { tálamo }(>1,5 \mathrm{~cm})\end{array}$ & & $\begin{array}{l}\text { Lobos frontal, parietal e } \\
\text { temporal }(<1,5 \mathrm{~cm})\end{array}$ \\
\hline $\begin{array}{l}\text { Triagem/ prevenção } \\
\text { primária }\end{array}$ & $\begin{array}{l}\text { Doppler } \\
\text { transcranial }\end{array}$ & Desconhecida & $\begin{array}{l}\text { Desconhecida (testes neuro-psicométricos, } \\
\text { estudos funcionais por imagens?) }\end{array}$ \\
\hline Tratamento & $\begin{array}{l}\text { Transfusões crônicas ou } \\
\text { transplante de medula óssea }\end{array}$ & $\begin{array}{l}\text { Cirurgia; transfusões } \\
\text { crônicas? }\end{array}$ & $\begin{array}{l}\text { Desconhecido } \\
\text { (Transfusões crônicas?) }\end{array}$ \\
\hline
\end{tabular}




\section{Laboratoriais}

- Hb basal abaixo de 7,5 g/dL com reticulocitose

- leucocitose acima de 15.000 / $\mu \mathrm{L}$ e plaquetose acima de $450.000 / \mu \mathrm{L}$

- $\quad$ sinais de asplenia funcional (presença de pits na membrana dos eritrócitos)

- Hb Fetal menor que 13\%, aos 2 anos de idade

- ausência de alfa talassemia

- alguns subtipos do HLA

Com o desenvolvimento de técnicas modernas de neuroimagem, é possível prever o risco de desenvolver AVC e detectar lesões "silenciosas" (ICS). Arteriografia cerebral contrastada foi a primeira técnica utilizada para o estudo dos grandes e pequenos vasos, mas a necessidade de preparo transfusional prévio, além de ser muito invasiva, encontra-se hoje substituída pela angiorressonância (ARM). As imagens de ressonância magnética nuclear (IRM) permitem diagnosticar as lesões residuais de infartos cerebrais silenciosos na substância branca e cinzenta. Assim foi possível diagnosticar aneurismas no polígono de Willis, estenoses, infartos cerebrais completos e incompletos e moyamoya. Com o desenvolvimento da ultra-sonografia Doppler, a velocidade de fluxo sangüíneo das grandes artérias cerebrais pode ser facilmente avaliada por medida não-invasiva, permitindo o estudo das carótidas internas, do sifão carotídeo e das porções proximais das artérias cerebrais média e anterior. ${ }^{4}$ Aumento de velocidade de fluxo significa estenose, e redução, oclusão ou suboclusão. O fluxo cerebral nas crianças é normalmente aumentado devido ao crescimento cerebral e necessidade de extração de oxigênio, e na anemia falciforme, também, devido à anemia. Consideram-se valores patológicos as velocidades acima de $170 \mathrm{~cm} / \mathrm{seg}$ (acima de 200 com outros tipos de Doppler) e abaixo de $70 \mathrm{~cm} / \mathrm{seg}$. Associando-se o Doppler Color Duplex com IRM e ARM podemos estudar a velocidade de fluxo, lesões anatômicas vasculares e lesões residuais. Aplicado aos pacientes com anemia falciforme, mostra lesões nos lobos frontais e parietais, assim como atrofia cerebral em 20\% dos casos. No AVCh, a tomografia computadorizada do crânio permite o diagnóstico em 100\% dos casos. $^{4}$

O tratamento do AVC agudo exige oxigenioterapia, controles de pressão arterial, desidratação, hipotermia e hiperglicemia, além de suporte respiratório e transfusão. As lesões de reperfusão da área isquêmica são particularmente danosas, com liberação de glutamato, cálcio intracelular, proteases, radicais livres e desencadeamento de inflamação. Agentes neuroprotetores não foram ainda testados, como os inibidores do glutamato.

O tratamento de escolha é a transfusão de eritrócitos com hemoglobina A, para reduzir a anemia, a viscosidade e a concentração de $\mathrm{Hb} \mathrm{S}$. Na presença de $\mathrm{Hb} \mathrm{A}$, há poucas recaídas (10\% a 20\% dos casos em regime transfusional crônico). ${ }^{12}$ As transfusões em longo prazo previnem a lesão endotelial causada pela anemia e hiperviscosidade. Sem trans- fusões crônicas, 2/3 dos casos de AVCi sofrem recorrência. As transfusões devem ser mantidas até os 18 anos de idade, procurando respeitar os alvos de hemoglobina (Hb) $12 \mathrm{~g} / \mathrm{dl}$ e concentração de Hb S igual ou inferior a 30\%. Após transfusão, a velocidade de fluxo na artéria cerebral média (ACM) diminui cerca de 20\% no estudo com Doppler. Três horas após, o hematócrito (Ht) encontra-se entre 29\% e 34\% com queda da viscosidade sangüínea. As transfusões devem ser iniciadas tão logo seja confirmado o diagnóstico de infarto cerebral. Como a vasculopatia cerebral é dinâmica, poderá haver melhora das imagens na ARM e novas lesões assintomáticas. AARM pode mostrar um alisamento do endotélio rugoso, mas com progressão das lesões nos grandes vasos. O infarto completo não melhora. Nas crianças maiores, lesões silenciosas continuam, com perda neuronal e deficiências neurológicas. Havendo parada das transfusões antes dos 10 anos de idade, certamente haverá recorrência de AVC. Havendo grande acúmulo de ferro, pode-se reduzir a concentração da Hb S pré-transfusional de $30 \%$ para 50\%. As transfusões devem ser de eritrócitos fenotipados e leucorreduzidos, sob a forma de transfusões simples crônicas, exsangüíneo ou eritrocitaférese. Na fase aguda do AVCi, esta última é o procedimento ideal, preferencialmente dentro das primeiras seis horas do início dos sintomas. ${ }^{13}$ As transfusões causam diversos efeitos adversos, tais como dificuldades de acesso venoso, má aderência à quelação do ferro transfusional, aloimunização antieritrocitária, transmissão de doenças infecciosas, além de problemas pessoais e familiares.

Utilizando Doppler e transfusão, Adams $(1998)^{14}$ demonstrou a possibilidade da prevenção primária do AVCi, que foi objeto de revisão por Hirst \& Wang (2006) na Cochrane Library. ${ }^{15}$ Há acentuada redução do risco nas crianças com Doppler alterado que recebem transfusões regulares, mantendo a $\mathrm{Hb} \mathrm{S}$ na maioria das vezes abaixo ou igual a 30\%. Os autores não conseguiram evidências com relação à prevenção secundária (após o primeiro AVCi), mas há relatos e observações ${ }^{16}$ sobre a redução das recorrências nas crianças regularmente transfundidas. Alguns países optaram por não transfundir, na falta de sangue de boa qualidade ou devido ao alto número de doadores com traço falciforme na população. Outras objeções devem-se a questionamentos sobre se não estaríamos colocando muitas crianças sob desnecessário risco transfusional, haja visto que o risco de desenvolver AVC é de $10 \%$ a $15 \%$ por ano entre aquelas com dois Doppler alterados sem transfusão, e de $0,5 \%$ a $1 \%$ por ano naquelas com transfusão. Ou seja, a grande maioria das crianças não desenvolve AVCi na ausência de transfusão. Daí a necessidade de complementar o estudo Doppler com imagens neurorradiológicas e estudar outros fatores de risco. A tentativa de suspender as transfusões após trinta meses no grupo de prevenção primária não foi bem sucedida, porque a maioria das crianças mostrou elevação do fluxo cerebral (STOP 2) com desencadeamento de AVCi em dois 
casos, reforçando, portanto, que as transfusões devem permanecer até os 18 anos de idade, ou indefinidamente. Ware (2004) $)^{12}$ relatou experiência bem sucedida com a substituição das transfusões pela hidroxiuréia e o uso de sangria (5 ml a $10 \mathrm{ml} / \mathrm{kg}$ cada duas a quatro semanas se $\mathrm{Hb}$ mantida acima de $7 \mathrm{~g} / \mathrm{dl}$ ) para redução do acúmulo de ferro transfusional. Kirkham (2006) $)^{17}$ fez levantamento dos estudos prospectivos em andamento sobre a substituição das transfusões por hidroxiuréia no AVC, na prevenção das lesões de ICS, do uso de aspirina e de suporte noturno de oxigênio. Os resultados não foram ainda publicados.

A hidroxiuréia (HU) via oral nas doses de $15 \mathrm{mg}$ a $35 \mathrm{mg} / \mathrm{kg} /$ dia pode ser usada em crianças maiores e adolescentes em doses diárias de $1.000 \mathrm{mg}$ a $1.500 \mathrm{mg}$. Promove aumento da Hb Fetal e redução dos reticulócitos. Ainda não se sabe se evita a progressão da vasculopatia, e alguns autores crêem que poderia substituir as transfusões no AVC, pois se constatou que reduz a amplitude das lesões na periferia das áreas pré-infartadas. ${ }^{4}$ Não há dados na prevenção da vasculopatia em crianças pequenas, de 3 ou 4 anos de idade, além do que a aderência das crianças ao tratamento é problemática. Em crianças com AVC após dez a quinze anos de transfusão, com grave aloimunização e hemossiderose, a hidroxiuréia é a única opção. ${ }^{4}$ Kratovil (2006) ${ }^{18}$ mostrou recentemente os efeitos favoráveis da HU na redução do fluxo cerebral pelo Doppler. Os efeitos colaterais da hidroxiuréia podem eventualmente limitar sua opção de uso.

O transplante de medula óssea compatível e relacionado (TMO) está disponível a uma minoria (10\% a 15\% dos casos nos EUA). Apesar de curativo, as lesões cerebrais estabelecidas não regridem. Atkins (2003) ${ }^{19}$ e Woodard $(2005)^{20}$ relatam casos de progressão da vasculopatia após transplantes bem sucedidos.

\section{Discussão e recomendações}

O objetivo destas condutas é preservar a normalidade da função cerebral, ou impedir a progressão da isquemia, conseqüentemente da perda neuronal, e das alterações funcionais. O primeiro passo é identificar as crianças sob risco de lesão das grandes e pequenas artérias cerebrais antes do aparecimento de deficiências neurológicas. É preciso utilizar a tecnologia de imagens neurorradiológicas, ou seja, a combinação dos dados sobre a velocidade do sangue com IRM/ ARM. É preciso avaliar os fatores de risco citados na literatura com os meios locais disponíveis, procurando caracterizar os "fenótipos de risco".

Pelos dados apresentados passamos a sugerir condutas baseadas em evidências (Cochrane Library), ${ }^{15}$ as publicadas por Powars (2000), ${ }^{2}$ Wong $(2005){ }^{4}$ e as resoluções do SCD Global Experts. ${ }^{1}$

- Toda criança aos 2 ou 3 anos com anemia falciforme deve ser avaliada para fatores de risco, com reavaliação anual.
- Havendo um ou mais fatores de risco, realizar o Doppler transcranial, complementado com IRM/ARM. Se os resultados forem normais, colocar em HU, monitorando fatores de risco anualmente. Aos 7 anos realizar estudo neuropsicológico. Refazer os estudos de neuroimagem se necessários.

- Doppler e neuroimagens anormais, TMO. Se bem sucedido, reavaliar aos 7 anos as funções neuropsicológicas.

- Não sendo possível TMO, transfusões crônicas de eritrócitos fenotipados leucorreduzidos (ver Rogers, 2006), ${ }^{21}$ procurando manter a $\mathrm{Hb} \mathrm{S}$ abaixo ou igual a $30 \%$, associando HU e quelação do ferro.

- Repetir Doppler/IRM/ARM após 1 ano e aos 10 anos de idade. Aos 7 anos, estudo neuropsicológico. Aos 10 anos, com imagens normais, podem-se interromper as transfusões, mantendo HU e a observação.

- Se imagens ainda anormais, manter transfusão e HU até os 18 anos. Após os 18 anos, manter em HU e observação.

O relatório final do Grupo latino-americano do SCD Global Experts And Regional Advisory Board (2006) ${ }^{1}$ sugere para os países participantes as seguintes medidas:

- Triagem das crianças utilizando a ultra-sonografia Doppler transcranial, apesar de ser teste pouco disponível e que necessita de treinamento da equipe médica.

- Fenotipagem de todas as crianças até os 6 meses de idade. Iniciar as transfusões com hemocomponente leucorreduzido. Se houver AVC prévio, manter $\mathrm{Hb} \mathrm{S}$ igual ou abaixo de $30 \%$ no primeiro ano e, posteriormente, em $50 \%$.

- Manter Hb em 10 g/dl, utilizando sangue de doadores sem traço $\mathrm{S}$ ou $\mathrm{C}$, mantendo as transfusões indefinidamente.

- Há dúvidas sobre a utilidade da HU.

- Quelação do ferro transfusional. Avaliar a sobrecarga com duas dosagens da ferritina, inicialmente, e depois a cada três meses, acrescida da saturação da transferrina. Conservar ferritina abaixo de $1.000 \mathrm{ng} / \mathrm{ml}$ utilizando os quelantes de ferro disponíveis.

- Monitorar as lesões de órgãos uma vez ao ano por meio de eletrocardiograma e ecocardiograma.

Estas outras recomendações, resumidas e modificadas do NIH22, sugerem que se avalie a possibilidade de:

- Realizar o estudo por meio do Doppler (DTCi) anual (ou IRM/ARM). Se sim, as crianças com valores elevados do Doppler devem ter confirmação com IRM/ARM.

- Se DTC e angiorressonância não forem disponíveis, devem ser avaliadas para fatores de risco, como, por exemplo, anemia grave, ataque isquêmico transitório (TIA) prévio, hipertensão arterial e antecedentes de síndrome torácica, ou outros, e receber hidroxiuréia. Não havendo fatores de risco, observação.

- Havendo confirmação com a ressonância, transfusões crônicas e hidroxiuréia concomitantes. TMO, havendo doador compatível. 
- Havendo lesões de ICS na IRM, hidroxiuréia.

- Promover programas de recuperação neurofuncional das crianças com deficiências.

\begin{abstract}
In children with sickle cell disease, cerebral arteries are prone to lesions that may cause deficiencies and poor quality of life. After the age of 20, new lesions may also occur. Besides stroke and silent cerebral ischemia, other lesions may occur. Radiologic images are necessary to diagnose and blood transfusions to treat. We reviewed the literature to choose best practices and guidelines to reduce morbidity and mortality and improve the quality of life of children with sickle cell disease. Risk factors identified from clinical and laboratory data and screening by Doppler ultrasonography and magnetic resonance must be used in order to make decisions about transfusion and iron chelation therapy. Rev. bras. hematol. hemoter. 2007;29(3):262-267.
\end{abstract}

Key words: Sickle cell disease; cerebral vascular disease; stroke.

\section{Referências Bibliográficas}

1. Guidelines and Clinical Practice for the Treatment of Sickle Cell Disease. Sickle Cell Disease Global Experts and Regional Advisory Board Latin America, Philadelphia, USA, http://www.pslgroup.com/ dg/26409E.htm, setembro de 2006.

2. Powars DR. Management of cerebral vasculopathy in children with sickle cell anaemia. Br J Haematol. 2000;108:666-78.

3. Adams RJ, Ohene-Frempong K, Wang W. Sickle cell and the brain. Hematology (American Society of Hematology Educacional Program). 2001:31-46.

4. Wong W-Y, Powars DR. Overt and incomplete (silent) cerebral infarction in sickle cell anemia: Diagnosis and management. Hematol Oncol Clin N Am. 2005;19:839-55.

5. Manci EA, Culberson DE, Yang Y-M et al. Causes of death in sickle cell disease: An autopsy study. Br J Haematol. 2003; 123 (2):359-65.

6. Serafim ESS, Albuquerque ES, Braga EES, Medeiros FJ. Análise dos óbitos dos pacientes com doença falciforme acompanhada no Hemocentro Dalton Cunha e Regional de Mossoró. Rev bras hematol hemoter. 2006;28 (supl. 2):1-221, p10 ref 024.

7. DeBaun MR, Mckinstry R, White D, Casella JF. Epidemiology and treatment of silent cerebral infarcts in sickle cell anemia. In Buchanan GR, DeBaun MR, Quinn CT, Steinberg MH. Sickle Cell Disease. Hematology (American Society of Hematology Educacional Program): 35-40, 2004.

8. Hoppe C. Defining stroke risk in children with sickle cell anaemia. Br J Haematol. 2004;128:751-66.

9. Stuart M, Nagel R. Sickle-cell disease. Lancet 2004;365:1343-60.

10. Hebbel RP. Examination of vascular pathobiology of sickle cell anemia. Microcirculation. 2004;11(2):99-100.

11. Sebastiani P, Ramoni MF, Nolan V et al. Genetic dissection and prognostic modeling of overt stroke in sickle cell anemia. Nature Genetics. 2005;37(4):435-40.

12. Ware RE, Zimmerman SA, Sylvestre PB, Mortier NA, Davis JS, Treem WR et al. Prevention of secondary stroke and resolution of transfusional iron overload in children with sickle cell anemia using hydroxyurea and phlebotomy. J Pediatr. 2004;145:346-52.
13. Swerdlow PS. Red cell exchange in sickle cell disease. Hematology (American Society of Hematology Educacional Program).2006: 48-53.

14. Adams RJ, McKie VC, Hsu L, Files B, Vichinsky E, Pegelow C et al. Prevention of a first stroke by transfusions in children with sickle cell anemia and abnormal results on transcranial Doppler ultrasonography. N Engl J Med. 1998;339:5-11.

15. Hirst C, Wang W. Blood transfusion for preventing stroke in people with sickle cell disease (Cochrane Review). In: The Cocherane Library, Issue 1, 2006, Oxford: Update software.

16. Platt O. Prevention and management of stroke in sickle cell anemia. Hematology (American Society of Hematology Educacional Program). 2006:54-57.

17. Kirkham F, Lerner NB, Noetzel M, DeBaun MR, Datta AK, Rees DC, et al. Trials in sickle cell disease. Pediatr Neurol. 2006;34: 450-8.

18. Kratovil T, Bulas D, Driscoll C, Speller-Brown B, McCarter R, Minniti C. Hydroxyurea therapy lowers TCD velocities in children with sickle cell disease. Pediatr Blood Cancer. 2006;47:894-900.

19. Atkins RC, Walters MC. Haematopoietic cell transplantation in the treatment of sickle cell disease. Expert Opin Biol Ther. 2003; 3(8):1215-24.

20. Woodard P, Helton KJ, Khan RB, Hale GA, Phipps S, Wang W et al. Brain parenchimal damage after haematopoietic stem cell transplantation for severe sickle cell disease. Br J Haematol. 2005; 129(4):550-2.

21. Rogers ZR. Review: Clinical Transfusion Management in sickle cell disease. Immunohematology. 2006;22(3):126-131.

22. National Institutes of Health. National Heart, Blood and Lung Institutes. Division of Blood Diseases and Resources. The Management of Sickle Cell disease. NIH Publication 02-217, $4^{\text {th }}$ ed, June 2002.

O tema apresentado e o convite ao autor constam da pauta elaborada pelo co-editor, prof. Rodolfo Delfini Cançado.

Avaliação: Co-editor e um revisor externo.

Publicado após revisão e concordância do editor.

Conflito de interesse: não declarado.

Recebido: 09/04/2007

Aceito: 15/05/2007 